\title{
The home and school environments, physical activity levels, and adiposity indices of school-age children
}

\author{
Patience K. Gaa ${ }^{1}$, Charles Apprey ${ }^{2}$, Reginald Annan ${ }^{3}$, Victor Mogre ${ }^{4}$, Victoria Pearl Dzogbefia ${ }^{5}$ \\ $1,2,3,5$ Department of Biochemistry and Biotechnology, College of Sciences, Kwame Nkrumah University of Science and \\ Technology, Ghana \\ ${ }^{4}$ Department of Health Professions Education and Innovative Learning, University for Development Studies, Ghana
}

\begin{tabular}{l} 
Article Info \\
\hline Article history: \\
Received Nov 20, 2018 \\
Revised Jan 18, 2019 \\
Accepted Feb 22, 2019 \\
\hline
\end{tabular}

\section{Keywords:}

Adiposity

Family environment

Ghana

Physical activity

School environment

School-age children

\begin{abstract}
The home and school environments as well as physical activity may be linked to the development of childhood obesity. We evaluated the home and school environments (HSEs), physical activity levels (PAL), television viewing (TVV) and their associations with adiposity indices of school-age children. This Cross-sectional study included children aged 6-12 years and their parents from Tamale, Ghana. HSEs and TVV were assessed using questionnaires. The physical activity questionnaire for children (PAQ-C) was used to assess children's PALs. Weight, height and waist circumferences were measured using standard tools. About $45 \%$ of children lived within a walking distance to parks or outdoor recreation centres. Majority of the parents considered their neighbourhoods to be safe for children to engage in physical activity. Only $27 \%$ of the schools had a food and nutrition policy, and more than $70 \%$ had a field for outdoor activities. Children watched TV for an average of 1.7 hours/day. Mean physical activity scores was 2.51 . The school-age children had mean (SD) BMI-for-age z-scores was -0.23(1.47). Time spent watching TV or playing video games was associated with children's BMI-for-age z-scores $(\beta=0.48, p=0.043)$, BMI $(\beta=2.28 p=0.005)$, and $\%$ body fat $(\beta=3.80, p=0.005)$. Child's level of activity was negatively associated with waist circumference $(\beta=-0.65, p<0.001)$. Lack of nutrition policy in schools was common. TVV hours predisposed children to excess weight whiles physical activity decreased the likelihood of being obese
\end{abstract}

Copyright $\odot 2019$ Institute of Advanced Engineering and Science. All rights reserved.

\section{Corresponding Author:}

Patience K. Gaa,

Department of Biochemistry and Biotechnology,

Kwame Nkrumah University of Science and Technology,

PMB, Kumasi, Ghana.

Email: lovenagaa@yahoo.com

\section{INTRODUCTION}

Obesity has become a global public health problem affecting both developed and developing countries and childhood obesity has been described as "the new pandemic of the millennium" [1]. Childhood obesity is directly associated with morbidity in children and has the potential to continue into adulthood, largely due to the likelihood of childhood eating and activity habits persisting into adulthood [2]. About 42 million children were either overweight or obese in 2015, a quarter of which lived in Africa (WHO, 2014). In Ghana, the 2014 Ghana Demographic and Health Survey (GDHS) reports a childhood overweight prevalence of $3 \%$.

It is generally considered that the home and school environments are important determinants of weight gain in children; making it an appropriate avenue for long-term obesity prevention programmes [3-4]. Fundamentally, parents act as providers, enforcers and role models for their children and as a result has 
an enormous influence on the lifestyles of their children [4-5]. No wonder public health interventions continuously focus on parents [4]. Almost all children spend the first two decades of their life in school, making the school setting an important health determinant [5]. The school is an important aspect of the social environment and also present important avenues within which children practice and adopt healthy habits [6]. The school setting can either reinforce or hinder health messages delivered through health education curricular [7]. Children's reception of nutrition education is largely depended on the contexts in which they learn about nutrition and healthy eating [8].

Physical activity and TVV are important determinants of overweight and obesity in children [9], [10]. Less physically active children are more likely to be overweight or obese compared to their physically active counterparts. According to Ebbeling, Pawlak, \& Ludwig [11] a lifestyle characterized by lack of physical activity and excessive inactivity (particularly television viewing) might cause obesity in children. Among children from Mexico City, obesity risk decreased by $10 \%$ for each hour per day of moderate-to-vigorous physical activity, and increased by $12 \%$ for each hour per day of television viewing [12]. To the best of our knowledge no study has investigated the together the home and school environments, physical activity levels, television viewing and their effect on the adiposity indices of school age children. We thus evaluated the home and school environments, physical activity levels, TVV and their associations with the adiposity indices of school-age children in the Tamale Metropolis.

\section{RESEARCH METHOD}

\subsection{Study design, study setting and study population}

This Cross-sectional study was conducted in primary schools located in the Tamale Metropolis of Ghana. Tamale is the capital city of the Northern Region of Ghana. Lying between $9^{\circ} 22^{\prime} \mathrm{N}$ and longitude $0^{\circ} 50^{\prime} \mathrm{W}$ and covering an area of about $922 \mathrm{~km} 2$, Tamale is about $600 \mathrm{~km}$ north of Accra, Ghana's capital city. Participants of this study included school-aged children recruited from 10 private and public schools in Tamale.

\subsection{Sample size}

A sample size of 316 children-parents pairs was recruited for the study. This number was arrived at based on the following formula adapted from the WHO STEPwise approach for chronic disease risk factor surveillance (STEPS) (World Health Organization, 2008): $n=Z 2$ (P(1-P))/e2, where Z=level of confidence (1.96 value for $95 \%$ confidence interval), $\mathrm{P}=$ baseline level of the indicators (from previous studies baseline prevalence of childhood obesity $=10 \%$ ), e = margin of error (for this 0.05 will be used because the baseline level of the indicators is not<0.10). Thus $n=1.9620 .10(1-0.10) / 0.052=200$. To cater for design effect, 200 was multiplied by $1.5=300$. A design effect of 1.5 is recommended for most surveys using complex designs other than simple random sampling (World Health Organization, 2008). Taking cognizance of a non-response of 5\% from previous studies, the final sample size was 300/0.95=316. Proportional allocation was used to determine the sample size for each of the schools. Thus schools with larger pupils had the largest sample size.

\subsection{Inclusion criteria} participate.

All children aged 6-12 years and were in any of the classes (i.e. primary 1 to 6) were eligible to

\subsection{Exclusion criteria}

Those younger than 6 years and were not in primary school were not eligible to participate.

\subsection{Sampling technique and participant recruitment}

From a list of schools within Tamale, 7 public and 3 private schools were selected using systematic random sampling techniques in which every 11th school was selected. Letters of permission were written to the heads of the selected schools to obtain access to the school. Pupils from all the classes (i.e. primary 1 to 6 ) were eligible to participate in the study. In schools that had two pairs of such classes, random sampling using the lottery technique was used to select one of the classrooms. Using a similar lottery technique children from the selected classrooms were chosen to take part in the study. Every child in the selected classroom was asked to randomly pick from a container that contained pieces of paper with either "Yes" or "No" written on them. If a child picked "Yes" that child was included in the study and the reverse was true if the child picked "No". The number of participants from each classroom and school depended on the population of children in the classroom such that classes with large population had larger numbers participating. Thus, ranges of between 20 to 30 children were selected from each of the schools. All selected children were taken through informed consent procedures introducing to them to the study as well as the risk

The home and school environments, physical activity levels, and adiposity indices of... (Patience K. Gaa) 
and benefits of participating. Every child was provided child assent consent form which was completed. Participation in the study was voluntary. All participating children were taken to a secluded area near (mostly under a tree) for them to fill up a questionnaire and also take their anthropometric measurements. The principal investigator with the help of the school authorities made sure the secured area had little distraction from other children who were not participating in the study. Upon completing the questionnaire and anthropometric measurements, participating children were given a parent questionnaire to be sent home for one of their parents to fill for them and returned next day to their class teacher. The principal investigator visited the school a day later and collected all the returned parent filled questionnaires. Data collection spanned from November, 2017 to January, 2018. All data collection procedures were approved by the Committee for Human Research Publication and Ethics of the Kwame Nkrumah University of Science and Technology with reference number (CHRPE/AP/490/17).

\subsection{Data collection methods}

Three structured questionnaires were used for data collection including the home environment questionnaire filled by a parent for the selected child, a school environment questionnaire filled by the head of the school and the physical activity questionnaire for children (PAQ-C).

\subsubsection{The home environment questionnaire}

Items of this questionnaire were derived from the Home Environment Interview (HEI) [13]. The HEI is a comprehensive measure of the home environment and has been used previously among parents with young children. It evaluates a series of physical and social aspects of the home food, activity and media environments. The physical and social aspects of activity and the media environments of the HEI were adopted for this study. It had items that assessed parental support/modelling of physical activity, parental TV viewing rules and parents' level of satisfaction with safety of their neighbourhood [14]. Parents' modelling of physical activity in the home environment was assessed by means of a questionnaire. In addition, parents were asked to assess the safety of their neighbourhood for physical activity using a questionnaire that were answered on a 5-point Likert scale. Parents responses were computed to yield a neighbourhood safety score. Demographic variables such as number of adults and children living with the child were also included into the parent questionnaire.

\subsubsection{The school environment questionnaire}

The food, nutrition and physical activity environment of the schools were assessed using a 25 -item questionnaire. The items of this questionnaire were derived from a previous publication [15]. It assessed the presence of food and nutrition policy for the school, the conduciveness of the school for physical activity and physical education, kinds of food sold in the school, the kind of food service ran in the school, among others. This questionnaire was filled by the head of the school.

\subsubsection{The physical activity level questionnaire for children}

The PAQ-C is a 10-item questionnaire that assesses physical activity levels of children within the last 7 days. It is a recall questionnaire that assesses different physical activities, activity during physical education classes, lunch break, recess, after school, in the evenings and during weekends [16]. The first item consists of a check list of 22 common leisure and physical activities including sports, leisure activities and games. It contains two blank spaces for children to include activities not included in the list. Children were asked to indicate the number of times they had engaged in the listed activities in the past 7 days. Options included "No, 1-2 times, 3-4 times, 5-6 times and 7 or more times". Scoring "No" activity to be 1 and "7 times or more" as 5 , the mean of all activities of the activity checklist was calculated to constitute a composite score for the first item. The remaining items (item 2 to 8 ) that evaluate activities engaged in by the child at certain periods of the day (PE, recess, lunch, right after school, evening, weekends, and describes you best) were also computed into an average composite score using the reported value that is checked off for each item (the lowest response activity being a 1 and the highest response activity being a 5). The overall total PAQ-C score is a composite value that calculates the mean of the nine item scores. The tenth item of the PAQ-C evaluates an unusual event that may prevent the child from engaging in regular physical activity and it is not usually included into the calculation of total PAQ-C scores. Demographic variables of age, sex, parent's educational level and current class were included into the questionnaire.

\subsubsection{Anthropometric measurements and adiposity indices}

Anthropometric measurements of weight, height, and waist circumference were measured. Weight and height was measured using a weight and height digital scale manufactured by Jactermac, 
Germany. Weight was measured to the nearest $0.1 \mathrm{Kg}$ and height to the nearest $\mathrm{cm}$. In both measurements, children wore light clothing without their shoes on. The weight and height digital scale were calibrated each day before the first measurement. Age- and sex-specific standard deviation scores were computed using the WHO Body-Mass-Index-for-age Z-scores by means of the WHO Anthroplus software for 5-19 year old using the World Health Organization (WHO) reference population, 2007 software. BMI was calculated as weight $(\mathrm{Kg})$ divided by height $(\mathrm{m})$ squared. Using a flexible tailor's tape measure waist circumference was measured to the nearest centimetre while children were in a standing position at the end of a gentle expiration. The anatomical landmarks used were: laterally, midway between the lowest portion of the rib cage and iliac crest and anteriorly, midway between the xiphoid process of the sternum and umbilicus [17]. Waist to height ratio (WHtR) was calculated as waist circumference (in $\mathrm{cm}$ )/height (in $\mathrm{cm}$ ). \%Body fat was computed using Deurenberg et al. [18] formula. $(1.51 \times \mathrm{BMI})-(0.70 \times \mathrm{Age})-(3.6 \times \mathrm{Sex})+1.4$, where sex was coded as 1 for males and 0 for females.

\subsection{Statistical analysis}

All data was entered into the statistical software IBM SPSS version 20.0. Data analysis were done using IBM SPSS version 20.0 together with Microsoft Excel. GraphPad version 4.0 was used to draw graphs. Descriptive statistics such as mean and standard deviation were used to describe and report all continuous variables. Frequencies, percentages and graphs were used to report all categorical variables. Student T-test and one-way ANOVA were used to determine univariate associations between continuous and categorical variables. Associations among continuous variables were determined using Pearson correlation analysis. Multivariate linear regression using the stepwise forward selection method was used to identify factors associated with the five adiposity indices (BMI-for-age z-scores, BMI, waist circumference, waist-for-height ration and $\%$ body fat). Five separate regression models were built as each of the five adiposity indices were entered as dependent variables and the same independent variables entered for all. In all statistical analysis, a $\mathrm{p}<0.05$ was considered significant.

\section{RESULTS}

\subsection{General characteristics of the school-age children}

Three hundred and sixteen (316) children completed the child questionnaire from which 299 were complete for analysis (Response rate $=95 \%$ ). Two hundred and sixty four parents/caregivers completed the family and home environment questionnaire with Response rate of $84 \%$. Table 1 presents the general characteristics of the school-aged children as well as the parents/caregivers. The children were predominantly female and more than $60 \%$ of them had both parents attaining SHS/Tertiary level of education. With a mean (SD) age of 9.30 years (SD 2.14 years), $61.0 \%$ of the children were aged 9-12 years of age. Mean number of children and adults living with a school-aged child were 4.71 (SD 3.98) and 4.92 (SD 3.62) respectively.

Table 1. General characteristics of the children

\begin{tabular}{cc}
\hline Variable & Frequency (\%) \\
Gender & $165(55.0 \%)$ \\
Female & $9.30(2.14)$ years \\
Mean (SD) Age & \\
Age categories & $117(39.0 \%)$ \\
6y-8y & $183(61.0 \%)$ \\
9y-12y & $4.71(3.98)$ \\
Mean (SD) number of children living with child & $4.92(3.62)$ \\
Mean (SD) number of adults living with child & \\
*Class of child (n=286) & $143(50 \%)$ \\
Lower primary (Grade 1-3) & $143(50 \%$ \\
Upper primary (Grade 4-6) & \\
*Mother's level of education (n=293) & $43(14.7 \%)$ \\
No formal education & $58(19.8 \%)$ \\
Primary/JHS & $192(65.5 \%)$ \\
SHS/Tertiary & \\
*Father's level of education & $34(11.6 \%)$ \\
No formal education & $56(19.1 \%)$ \\
Primary/JHS & $203(69.3 \%)$ \\
SHS/Tertiary &
\end{tabular}

The home and school environments, physical activity levels, and adiposity indices of... (Patience K. Gaa) 


\subsection{Children's home environments}

Parents of the school-age children were asked to report the conduciveness of the home environment for the child to be physically active. As shown in Table $245.2 \%$ of the parents said they lived within a walking distance or short drive to parks or outdoor recreation centres and $58.9 \%$ had a garden or outdoor space for child to play. About $50 \%$ of the parents said their children had usable bicycle/tricycle/wheeled toy, $59 \%$ said they had a garden or outdoor space for child to play and only $16 \%$ said they had a usable play equipment for the child to play with at home. A mean (SD) physical activity modelling composite score of 2.91(0.84) was recorded out of a score maximum score of 5. A mean (SD) neighbourhood safety score of 3.92(0.98) was recorded.

Table 2. Assessment of the physical activity environment of the child's home

\begin{tabular}{|c|c|}
\hline Variable & Frequency $(\%)$ \\
\hline \multicolumn{2}{|l|}{ Presence of parks or outdoor recreation centers within walking distance or short drive from home $(\mathrm{n}=261)$} \\
\hline Yes & $118(45.2 \%)$ \\
\hline No & $124(46.7 \%)$ \\
\hline Don't know & $19(7.3 \%)$ \\
\hline \multicolumn{2}{|l|}{$\begin{array}{l}\text { Availability of indoor recreation centers (e.g. gym, indoor soft play) } \\
\text { that are within a walking distance or short drive }(n=259)\end{array}$} \\
\hline Yes & $68(26.3 \%)$ \\
\hline No & $164(63.3 \%)$ \\
\hline Don't know & $27(10.4 \%)$ \\
\hline \multicolumn{2}{|l|}{ Has a garden or outdoor space for child to play $(n=263)$} \\
\hline Yes & $155(58.9 \%)$ \\
\hline No & $108(41.1 \%)$ \\
\hline \multicolumn{2}{|l|}{ Has usable play equipment (e.g. swings, slides, climbing frames, trampolines) in your garden $(n=262)$} \\
\hline Yes & $41(15.6 \%)$ \\
\hline No & $221(84.4 \%)$ \\
\hline \multicolumn{2}{|l|}{ Child has usable bicycle, tricycle, scooter or wheeled toy $(n=248)$} \\
\hline 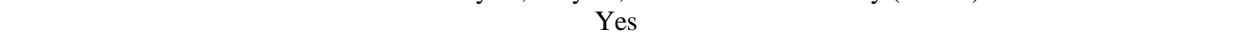 & $123(49.6 \%)$ \\
\hline No & $125(50.4 \%)$ \\
\hline \multicolumn{2}{|l|}{ Parental modeling of activity } \\
\hline Item & Mean (SD) \\
\hline Encourages child to do physical activity $(n=263)$ & $2.94(1.22)$ \\
\hline Frequently plays physical activity or play sports with child $(n=264)$ & $2.67(1.22)$ \\
\hline Frequently transport child to place for child to do physical activity $(n=263)$ & $2.49(1.27)$ \\
\hline Participates in physical activity with child $(n=257)$ & $2.90(1.24)$ \\
\hline Tells child about the benefits of being physical fit $(n=254)$ & $3.40(1.28)$ \\
\hline Being physically active in front of child $(n=252)$ & $3.12(1.30)$ \\
\hline Parental modeling of activity total score $(n=264)$ & $2.91(0.84)$ \\
\hline Parents/caregivers' perception of the house and neighbourhood safety for the performance of physical activity & Mean (SD) \\
\hline Satisfied with the safety of your neighborhood $(n=255)$ & $3.79(1.26)$ \\
\hline Ease of walking in the neighborhood $(n=259)$ & $4.20(1.24)$ \\
\hline Ease of bicycling in the neighborhood $(n=259)$ & $3.99(1.41)$ \\
\hline Total neighborhood safety score $(n=260)$ & $3.92(0.98)$ \\
\hline
\end{tabular}

\subsection{Food, nutrition and physical activity environment of children's schools}

Only $26.7 \%$ of the schools had a nutrition/food policy, from which all of them said such a policy was moderately effective in promoting healthy eating and increasing children's participation in physical activity as Shown in Table 3. None of the schools had a gymnasium or hall for physical activity but more than $70 \%$ of the schools had more than 1 field. Sweets were sold in the majority of the schools, $56.0 \%$ had contractors run for profit food service and none of the schools used food as means of fundraising. In order of frequency, co-curricular activities carried out by the schools included football (100\%), athletics $(79.0 \%)$, dancing $(56.0 \%)$, basketball $(33.7 \%)$, cycling $(17.7 \%)$, aerobics $(14.3 \%)$, tennis $(14.0 \%)$, swimming $(11.35)$ and netball $(9.3 \%)$. 
Table 3. Assessment of the food, nutrition and physical activity environment of children's schools

\begin{tabular}{cc}
\hline Variable & Frequency (\%) \\
Yes & $80(26.7 \%)$ \\
No & $220(73.3 \%)$ \\
School has a nutrition/food policy & \\
None & $43(14.3 \%)$ \\
1 field & $218(72.7 \%)$ \\
2 fields & $39(13.0 \%)$ \\
Yes & $118(42.8 \%)$ \\
No & $158(57.2 \%)$ \\
School has a daily fitness programme (n=276) & $71(23.7 \%)$ \\
Type of food service/canteen lunch order provided by school & $168(56.0 \%)$ \\
School run for profit canteen & $61(20.3 \%)$ \\
Contractors run for profit (this includes food vendors) & \\
No food service & $161(62.9 \%)$ \\
Sale of sweets in the school & $95(37.1 \%)$ \\
Yes & No \\
\hline
\end{tabular}

\subsection{Assessment of the physical activity levels of the children}

Mean (SD) and median physical activity scores for the children were 2.51(0.48) and 2.52(1.45-3.76) respectively. The most commonly reported sports and activities (i.e. for item 1 of the PAQ-C) in order of frequency were walking (2.70), bicycling (2.24), football (2.16), “ampe” (2.01), jogging (1.83) and dance (1.81). PAQ scores significantly differed by level of mother's education in that children's whose mothers had low level of education reported higher levels of physical activity compared to their counterparts whose mothers had high level of education $(1.57(0.23)$ versus $1.49(0.30) ; \mathrm{F}=5.08, \mathrm{p}=0.025)$. PAQ scores also differed significantly by gender with boys being more physical active than girls (girls=1.48(0.27), boys=1.58(0.29), $\mathrm{F}=11.23$, $\mathrm{p}=0.001)$. There were no significant differences when PAQ scores were compared with child's class, father's level of education, age and type of school.

\subsection{Assessment of children's media use and television viewing}

Shown in Table 4, mean (SD) number of working TVs, DVD/VCR players, and computers were 2.31(2.23), 1.57(1.72) and 1.34(1.29) respectively. Sixty-nine percent of the parents reported the presence of cable/satellite TV at home, $27.6 \%$ said the child had a working TV in his/her bedroom and more than $70 \%$ had rules around TVV. Thirty-three percent said they rewarded child's good behaviour with increased TVV time and $71 \%$ reduced TVV or computer use time when child is naughty.

Table 4. Children's media use and TV viewing

\begin{tabular}{cc}
\hline Variable & Mean (SD) \\
\hline Number of hours spent watching TV or watching video games $(\mathrm{n}=186)$ & $1.72(1.60)$ \\
Number of working TVs $(\mathrm{n}=226)$ & $2.31(2.23)$ \\
Number of DVD or VCR players $(\mathrm{n}=200)$ & $1.57(1.72)$ \\
Number of computers/laptops $(\mathrm{n}=236)$ & $1.34(1.29)$ \\
Type of media & $0.71(1.53)$ \\
Chumber of working games consoles (e.g. Play Station, etc) $(\mathrm{n}=231)$ & Frequency $(\%)$ \\
Yes & $165(68.5 \%)$ \\
No & $76(31.5 \%)$ \\
Child has a working TV in his/her bedroom $(\mathrm{n}=254)$ & $70(27.6 \%)$ \\
Yes & $184(72.4 \%)$ \\
No & $65(41.7 \%)$ \\
Child has a laptop/computer in his/her bedroom $(\mathrm{n}=156)$ & $91(58.3 \%)$ \\
Yes & $32(38.1 \%)$ \\
No & $52(61.9 \%)$ \\
Child has a games console in his/her bedroom $(\mathrm{n}=84)$ & $193(77.2 \%)$ \\
Yes & $57(22.8 \%)$ \\
No & $84(33.3 \%)$ \\
Has rules around TV watching or computer use $(\mathrm{n}=250)$ & $168(66.7 \%)$ \\
Yes & $179(71.0 \%)$ \\
Yo & $73(29.0 \%)$ \\
\hline
\end{tabular}

The home and school environments, physical activity levels, and adiposity indices of... (Patience K. Gaa) 


\subsection{Adiposity indices of the children and prevalence of overweight and obesity}

Anthropometric measurements of weight, height and Waist Circumference (WC) of the school-age children were taken and computed into adiposity indices such as Body Mass Index (BMI), BMI-for-age z-scores (BAZ), \%body fat (\%BF) and waist-to-height ratio (WHtR). The school-age children had mean (SD) BMI, BAZ, WC, \%BF and WHtR values of $16.74(4.49) \mathrm{Kg} / \mathrm{m}^{2},-0.23(1.47), 61.53(7.92) \mathrm{cm}$, 18.53(5.83) and 0.46(0.05) respectively. BMI, BAZ, \%BF, WC and WHtR of the school-aged were stratified by gender, child's class, parents' level of education and type of school and compared using student t-test. Mean (SD) waist circumference differed by level of class of the children. Children in the upper primary (63.84(8.54) had significantly $(\mathrm{F}=23.56, \mathrm{p}<0.001)$ higher waist circumferences than those in the lower primary $(59.40(6.83) \mathrm{cm})$. WHtR scores also differed by level of class as those in lower primary had lower WHtR values compared to their counterparts in upper primary $(0.47(0.04)$ versus $0.45(0.05), \mathrm{p}<0.001$, $\mathrm{F}=13.20)$. \% BF significantly differed by level of mother's education with children whose mothers had higher education had higher BAZ values (17.57(4.97) versus 19.10(6.24), $\mathrm{F}=4.55, \mathrm{p}=0.034)$. BAZ differed by gender (girls=0.06, boys $=-0.62 ; \mathrm{F}=15.54, \mathrm{p}<0.001$ ). In addition, $\% \mathrm{BF}$ differed significantly by gender (girls=20.54(5.69), boys=16.05(5.00), $\mathrm{F}=51.19, \mathrm{p}<0.001)$.

\subsection{Bivariate associations}

When PAQ scores were correlated with adiposity indices significant associations were observed. PAQ scores correlated negatively with BAZ $(\mathrm{r}=-0.141, \quad \mathrm{p}<0.05), \quad \mathrm{WC}(\mathrm{r}=-0.124, \quad \mathrm{p}<0.05)$, WHtR $(r=-0.119, \mathrm{p}<0.05)$ and \%BF $(r=-0.219, \mathrm{p}<0.05)$ of the children. Parents reported number of working TVs in the home correlated positively with BMI $(r=0.164, p=0.014)$, BAZ $(r=0.153, p=0.022)$, $\mathrm{WHtR}(\mathrm{r}=0.170, \mathrm{p}=0.011)$, and $\% \mathrm{BF}(\mathrm{r}=0.141, \mathrm{p}=0.034)$ but did not correlate significantly with the PAQ scores of the children $(-0.010, \mathrm{p}=0.886)$. WC values differed by parents' report of having rules for watching $\mathrm{TV}$ in that those who had rules had higher WC values than those who did not have rules (61.70 (7.63) versus 59.45 (6.46), $\mathrm{F}=4.04, \mathrm{p}=0.046)$. \% BF differed by child having a bicycle/wheeled toy in that those who had had higher \%BF than those who did not have (19.13 (6.51) versus 17.48 (4.49), $\mathrm{F}=5.32, \mathrm{p}=0.022$ ). WHtR also differed by child having a bicycle/wheeled toy as children who had had lower WHtR values compared to their counterparts who did not have (0.45 (0.05) versus 0.46 (0.05), $\mathrm{p}=0.007, \mathrm{~F}=7.30)$. There was a positive correlation between parents playing sport with child and PAQ scores $(r=0.125, p=0.043)$ of the children. Parents' neighbourhood safety score were not significantly associated with the PAQ scores of the children as well as the adiposity measures of BAZ ( $\mathrm{r}=0.015, \mathrm{p}=0.793)$, BMI $(\mathrm{r}=-0.014, \mathrm{p}=0.807)$, WC ( $\mathrm{r}=-0.053, \mathrm{p}=0.357)$, WHtR $(\mathrm{r}=-0.003, \mathrm{p}=0.959)$, and \%BF scores $(\mathrm{r}=-0.037, \mathrm{p}=0.522)$ of the children.

Children from schools that had a food policy had higher BAZ scores than children who came from schools that did not have a food policy $(0.13$ (1.35) versus -0.38 (1.57), F=6.75, p=0.010). BAZ scores differed by the kind of canteen service run by the school in that children from schools that had a canteen that runs for profit $(0.26)$ had significantly $(\mathrm{F}=5.45, \mathrm{p}=0.005)$ higher $\mathrm{BAZ}$ scores than their counterparts from schools that did not have a food service $(-0.36)$ or had food vendors $(-0.52)$

\subsection{Multivariate associations}

Table 5 presents the results of the multivariate linear regression of factors associated with the five adiposity indices i.e. BMI-for-age z-scores, BMI, waist circumference, WHtR, and \%BF). The results showed a significant association between time spent watching TV or using computer with three adiposity indices: BMI-for-age z-scores $(\beta=0.48, p=0.043), B M I(\beta=2.28 p=0.005)$, and $\%$ body fat $(\beta=3.80, p=0.005)$. A significant negative relationship was found between child's level of activity and waist circumference $(\beta=-0.65, \mathrm{p}<0.001)$ as well as WHtR $(\beta=-0.01, \mathrm{p}<0.001)$. A positive association was found between reported availability of indoor recreation centres and BMI $(\beta=4.32, p=0.003)$ and \%body fat $(\beta=6.07, p=0.018)$. 
Table 5. Multivariate analysis of factors associated with adiposity indices of the children (BAZ, BMI, waist circumference, waist-to-height ratio and \% body fat)

\begin{tabular}{|c|c|c|c|c|c|c|}
\hline Variable & $\mathrm{F}$ & $\mathrm{B}$ & $\begin{array}{l}\text { SE } \\
\text { of } \beta\end{array}$ & $\begin{array}{c}\mathrm{p}- \\
\text { value }\end{array}$ & $\begin{array}{l}\text { Partial } \\
\text { correlation }\end{array}$ & $\begin{array}{l}\text { Adjusted } \\
\mathrm{R}^{2}\end{array}$ \\
\hline BMI-for-age z-scores & 45.47 & & & & & 0.92 \\
\hline Has usable play equipment & & -6.05 & 0.54 & $<0.001$ & -0.94 & \\
\hline $\begin{array}{c}\text { Number of working games consoles (e.g } \\
\text { Play Station, etc) }\end{array}$ & & 0.47 & 0.05 & $<0.001$ & 0.94 & \\
\hline Number of DVD or VCR players & & 0.42 & 0.06 & $<0.001$ & 0.88 & \\
\hline Presence of problematic foods & & -0.18 & 0.03 & $<0.001$ & -0.81 & \\
\hline $\begin{array}{l}\text { Time spent watching TV or using } \\
\text { computer }\end{array}$ & & 0.48 & 0.22 & 0.043 & 0.51 & \\
\hline Body mass index & 10.34 & & & & & 0.50 \\
\hline Availability of indoor recreation centres & & 4.32 & 1.25 & 0.003 & 0.64 & \\
\hline $\begin{array}{l}\text { Time spent watching TV or using } \\
\text { computer }\end{array}$ & & 2.28 & 0.70 & 0.005 & 0.62 & \\
\hline Waist circumference & 10.75 & & & & & 0.51 \\
\hline Child's level of activity & & -0.65 & 0.14 & $<0.001$ & -0.75 & \\
\hline Has laptop at home & & -2.97 & 0.88 & 0.004 & -0.63 & \\
\hline Waist-to-height ratio & 14.49 & & & & & 0.74 \\
\hline Child's age & & -0.17 & 0.01 & $<0.001$ & -0.77 & \\
\hline Child's level of activity & & -0.01 & 0.01 & $<0.001$ & -0.80 & \\
\hline Has laptop at home & & -0.02 & 0.01 & 0.008 & -0.62 & \\
\hline Neighbourhood safety score & & 0.02 & 0.01 & 0.041 & 0.50 & \\
\hline \%Body fat & 10.87 & & & & & 0.61 \\
\hline Sex of child & & 5.87 & 2.30 & 0.021 & 0.54 & \\
\hline $\begin{array}{l}\text { Time spent watching TV or using } \\
\text { computer }\end{array}$ & & 3.80 & 1.18 & 0.005 & 0.63 & \\
\hline Availability of indoor recreation centres & & 6.07 & 2.31 & 0.018 & 0.55 & \\
\hline
\end{tabular}

\section{DISCUSSION}

\subsection{The family and home environment and associations with adiposity indices of the children}

An important finding of this study was that, majority of the parents reportedly did not have parks or outdoor recreation centres for children to play or perform some form of physical activity. Furthermore, most parents did not also have usable play equipment and wheeled toys that children could play to increase their physical activity levels. Such facilities create a conducive environment for children to play and run around thereby increasing their physical activity levels.

Relatedly, the availability of parks and recreation centres (such as gyms) is an important component of the built environment for the promotion of healthy weight among children [19]. Assumingly, the presence of these parks and recreation centres in the neighbourhood provide conducive environments for participation in physical activity which may help maintain healthy weight in children. However, in this study, availability of indoor recreation centres (e.g. gym, indoor soft play) that are within a walking distance or short drive within children's neighbourhood was positively associated with two adiposity indices i.e. \%body fat and body mass index. Studies reporting the association between availability of parks and recreation centres with adiposity have reported mixed results. While some studies report a negative association [20] some other studies have either reported a positive association consistent with the findings of this study or no association at all [21-22]. Varying methods of defining the location of parks and recreation centres have been reportedly blamed for the conflicting findings. In addition socio-economic status and ethnicity/race have also been blamed for the differences. reported that higher playground availability was associated with lower BMI percentile for White and high socio-economic girls but higher BMI percentile for African American and low socio-economic girls [23]. It thus suggests that factors other than neighbourhood safety may be contributing to the association between neighbourhood safety and adiposity of children. Obviously patronage of some of the recreation centres such as gyms may involve some financial costs that some parents may not be able to honour.

Another important finding of this study was that reported availability of useable play equipment such as swings, slides, climbing frames, trampolines and among others was significantly associated with lower BMI-for-age $\mathrm{z}$ scores. Children playing with this type of play equipment probably increased the physical activity levels of children which has been shown to be associated with lower weight status in this study. Children should thus be encouraged to participate in such type of plays and parents should also be encouraged to acquire such type of play equipment at home.

\subsection{The school environment and adiposity indices}

We found in this study that the physical activity environments of most of the schools were generally conducive for children to engage in a moderate-to-vigorous level of physical activity while in school. 
This assertion is supported by the following two major findings: 1) more than $70 \%$ of the schools had at least one field for children to play and 2) all of the schools engaged in at least one co-curricular activity such as soccer, dancing, aerobics, athletics, cycling, and among others. All of these provided opportunities for children to engage in physical activity. It is, however, worrying that only $43 \%$ of the schools had a daily fitness programme. A school environment is a place that children learn all sorts of habits including healthy dietary and physical activity habits. The availability of a daily fitness programme will encourage children to develop a daily habit of engaging in some form of physical activity which they maintain up to adulthood.

Concerning the food and nutrition environment of the school, it was worrying that only $27 \%$ of the schools had a food and nutrition policy. This is probably due to school authorities not recognising the importance of such policies. The absence of these policies implies the school might not be able to control the kind of foods that are sold in the school and will not also be able to determine how healthy those foods are for the school children. Sweets were also sold in more than $60 \%$ of the schools studied. This allows children to have easy access to these types of food in the school which may increase their likelihood of gaining weight.

Interestingly, children from schools that had for-profit canteens reportedly had higher BMI-for-age Z-scores compared to their counterparts from schools that had other forms of food service such as contractors or did not have a food service at all. Although this association was not significant in the multivariate analysis, the presence of canteens in the school increases opportunities for children to have easy access to food apart from the meals they may bring from home which may increase their energy consumption thereby resulting in increased weight gain.

\subsection{Physical activity levels and its association with the adiposity indices of the children}

The physical activity levels of the children as shown by the average PAQ scores of 2.3 (from a maximum score of 5) suggests the children had moderate level of physical activity. These findings are consistent with the 2.34 reported among Senegalese children aged 8 to 11 years and the moderate level of physical activity reported among children from Ile-Ife, Nigeria [24]. Consistent with previous studies boys were significantly more active than girls [25-27]. The PAQ scores of the children correlated negatively with four adiposity indices of the children (i.e. BAZ, WC, WHtR and \%BF). This is in consonance with those of previous studies [28-31]. These findings suggest the important role of increased physical activity in reducing weight gain in children and further support the widely accepted recommendation for children to participate in regular physical activity.

\subsection{Children's TVV, media use and adiposity}

The school-age children watched television for an average of $1.71 \mathrm{~h} /$ day although every household reportedly had an average of 2 working television sets. This is relatively lower than the 3.5/day TVV hours among 7-11 year old children in Brazil [32] and the 2.7h/day among a sample of 680 children from Mexico City [33], but higher than the $1.23 \mathrm{~h}$ /day TVV hours reported among a sample of 1926 children aged 4-12 years from Australia [34]. The differences may be related to variations in television programming relevance and appeal or cultural differences in viewing habits.

Previous cross-sectional studies among children from Ghana [35-37], sub-Saharan Africa [38] and other parts of the world [10, 33, 39-40] have shown longer duration of television viewing (TVV) being associated with childhood overweight and obesity. These associations were confirmed in this study in that the TVV hours of the children was associated with increased levels of three adiposity indicators (i.e. BMI-for age z-scores, BMI and \% Body fat). TVV may thus be an important determinant of weight gain in children.

\subsection{Limitations and strengths}

This study is not without limitations. Its cross-sectional nature makes it difficult to establish causality. The use of self-reporting makes the findings prone to recall bias as well as social-desirability bias. However, the use of previously validated questionnaires may have reduced the effect of these biases. The study consists of participants from a single setting which may affect the generalisability of the findings. The findings this study provides information on the relationship between the eating behaviours of fathers' and the adiposity measures of their children- a relationship that has been rarely reported in the scientific literature. Finally, the use of several measures of adiposity enabled a relatively thorough evaluation of the influence of the family, home and school environments on the children's adiposity. 


\section{CONCLUSION}

The school environments were conducive for children to engage in physical activity although there were a few characteristics present that could predispose children to weight gain. The homes of most of the children predisposed them to the sedentary lifestyle of watching TV, playing video games. The physical activity levels of the children were generally moderate. Number of hours children spent watching TV/using computer was the most important contributor to children's adiposity.

\section{ACKNOWLEDGEMENTS}

Authors wish to thank the teachers and pupils of the schools that participated in the study. In addition authors wish to thank parents of children who found time to fill the questionnaires given them by their children.

\section{REFERENCES}

[1] Kimm SY, Obarzanek E. Childhood obesity: a new pandemic of the new millennium. Pediatrics. 2002:110(5):1003-1007.

[2] Dietz WH. Health consequences of obesity in youth: childhood predictors of adult disease, Pediatrics. 1998:101(Supplement 2):518-525.

[3] Davison KK, Birch LL., Childhood overweight: a contextual model and recommendations for future research, Obesity reviews, 2001;2(3):159-171.

[4] Golan M., Parents as agents of change in childhood obesity-from research to practice, Pediatric Obesity. 2006;1(2):66-76.

[5] Glanz K, Lankenau B, Foerster S, et al. Environmental and policy approaches to cardiovascular disease prevention through nutrition: opportunities for state and local action, Health Education Quarterly, 1995:22(4):512-527.

[6] Parcel GS, Simons-Morton B, O'Hara NM, et al., School promotion of healthful diet and physical activity: impact on learning outcomes and self-reported behavior, Health education quarterly, 1989:16(2):181-199.

[7] Shilton T, Cortie B., School heart health promotion, National Heart Foundation of Australia's activities, Hygie. 1992, 11(1):11.

[8] Crockett SJ, Sims LS., Environmental influences on children's eating, Journal of Nutrition Education. 1995, 27(5):235-249.

[9] Brown JE, Nicholson JM, Broom DH, et al., Television Viewing by School-Age Children: Associations with Physical Activity, Snack Food Consumption and Unhealthy Weight [Article], Social Indicators Research. 2011;101(2):221-225, doi: 10.1007/s11205-010-9656-x.

[10] Rutherford L, Brown JE, Skouteris H, et al., Screen media, parenting practices, and the family environment in Australia: A longitudinal study of young children's media use, lifestyles, and outcomes for healthy weight [Article], Journal of Children and Media, 2015;9(1):22-39, doi: 10.1080/17482798.2015.997101.

[11] Ebbeling CB, Pawlak DB, Ludwig DS., Childhood obesity: public-health crisis, common sense cure, The lancet. 2002:360(9331):473-482.

[12] Hernández B, Gortmaker SL, Colditz GA, et al., Association of obesity with physical activity, television programs and other forms of video viewing among children in Mexico City, International journal of obesity, 1999;23(8):845.

[13] Bryant MJ, Ward DS, Hales D, et al., Reliability and validity of the Healthy Home Survey: a tool to measure factors within homes hypothesized to relate to overweight in children, International Journal of Behavioral Nutrition and Physical Activity, 2008;5(1):23.

[14] Schrempft S, van Jaarsveld CH, Fisher A, et al., The obesogenic quality of the home environment: associations with diet, physical activity, TV viewing, and BMI in preschool children, PloS one, 2015;10(8):e0134490.

[15] Carter M-A, Swinburn B, Measuring the 'obesogenic'food environment in New Zealand primary schools, Health promotion international, 2004;19(1):15-20.

[16] Kowalski KC, Crocker PR, Donen RM, The physical activity questionnaire for older children (PAQ-C) and adolescents (PAQ-A) manual, College of Kinesiology, University of Saskatchewan, 2004;87(1):1-38.

[17] Lohman T, Applicability of body composition techniques and constants for children and youths, Exercise and sport sciences reviews, 1986;14:325-357.

[18] Deurenberg P, Weststrate JA, Seidell JC, Body mass index as a measure of body fatness: age-and sex-specific prediction formulas, British journal of nutrition, 1991;65(2):105-114.

[19] McCarthy SM, Hughey SM, Kaczynski AT, Examining Sociodemographic Differences in Playground Availability and Quality and Associations with Childhood Obesity, Childhood Obesity, 2017;13(4):324-331.

[20] Gordon-Larsen P, Nelson MC, Page P, et al., Inequality in the built environment underlies key health disparities in physical activity and obesity, Pediatrics, 2006;117(2):417-424. 
[21] Norman GJ, Nutter SK, Ryan S, et al., Community design and access to recreational facilities as correlates of adolescent physical activity and body-mass index, Journal of physical activity and health, 2006;3(s1):S118-S128.

[22] Liu GC, Wilson JS, Qi R, et al., Green neighborhoods, food retail and childhood overweight: differences by population density, American Journal of Health Promotion, 2007;21(4_suppl):317-325.

[23] Hughey SM, Kaczynski AT, Child S, et al., Green and lean: Is neighborhood park and playground availability associated with youth obesity? Variations by gender, socioeconomic status, and race/ethnicity, Preventive medicine, 2017, 95:S101-S108.

[24] Ribeiro IDC, Taddei JAA, Colugnatti F, et al., Obesity among children attending elementary public schools in São Paulo, Brazil: a case--control study, Public Health Nutrition, 2003;6(7):659-663, PubMed PMID: 106736400. Language: English, Entry Date: 20040521, Revision Date: 20161128, Publication Type: journal article.

[25] Carter LM, Whiting SJ, Drinkwater DT, et al., Self-reported calcium intake and bone mineral content in children and adolescents, Journal of the American College of Nutrition, 2001, 20(5):502-509.

[26] Crocker PR, Eklund RC, Kowalski KC, Children's physical activity and physical self-perceptions, Journal of sports sciences, 2000, 18(6):383-394.

[27] Diouf A, Thiam M, Idohou-Dossou N, et al. Physical activity level and sedentary behaviors among public school children in Dakar (Senegal) measured by PAQ-C and accelerometer: Preliminary results, International journal of environmental research and public health, 2016;13(10):998.

[28] Vilchis-Gil J, Galván-Portillo M, Klünder-Klünder M, et al, Food habits, physical activities and sedentary lifestyles of eutrophic and obese school children: A case-control study [Article], BMC Public Health, 2015;15(1), doi: 10.1186/s12889-015-1491-1.

[29] Wright K, Giger JN, Norris K, et al. Impact of a nurse-directed, coordinated school health program to enhance physical activity behaviors and reduce body mass index among minority children: A parallel-group, randomized control trial, International Journal of Nursing Studies, 2013 June;50(6):727-737. doi: http://dx.doi.org/10.1016/j.ijnurstu.2012.09.004. PubMed PMID: 52231589.

[30] Katzmarzyk PT, Barreira TV, Broyles ST, et al., Relationship between lifestyle behaviors and obesity in children ages 9-11: Results from a 12-country study [Article], Obesity, 2015;23(8):1696-1702, doi: 10.1002/oby.21152.

[31] Baruki SBS, Rosado LEFPDL, Rosado GP, et al., Association between nutritional status and physical activity in Municipal Schools in Corumba - MS, [Portuguese, English], Revista Brasileira de Medicina do Esporte, 2006 March/April;12(2):80e-84e, PubMed PMID: 46743348.

[32] Mazaro IA, Zanolli Mde L, Antonio MA, et al., Obesity and cardiovascular risk factors in school children from Sorocaba, SP, Rev Assoc Med Bras (1992), 2011 Nov-Dec:57(6):674-80, PubMed PMID: 22249548, eng por.

[33] Lopez-Barron RG, Jimenez-Cruz A, Bacardi-Gascon M. Modifiable environmental obesity risk factors among elementary school children in a Mexico-us border city, Nutr Hosp, 2015 May 01;31(5):2047-53, doi: 10.3305/nh.2015.31.5.8669, PubMed PMID: 25929373, eng.

[34] Van Zutphen M, Bell AC, Kremer PJ, et al. Association between the family environment and television viewing in Australian children, J Paediatr Child Health, 2007 Jun;43(6):458-63, doi: 10.1111/j.1440-1754.2007.01111.x. PubMed PMID: 17535176, eng.

[35] Mogre V, Gaa PK, Abukari RNS, Overweight, obesity and thinness and associated factors among school-aged children (5-14 years) in Tamale, Northern Ghana, European Scientific Journal, ESJ, 2013;9(20).

[36] Mogre V, Aneyire E, Gyamfi E, Physical activity and BMI status of school-age children in Tamale, Northern Ghana, Pakistan Journal of Nutrition, 2013, 12(5):484.

[37] Amidu N, Owiredu W, Saaka M, et al. Determinants of childhood obesity among basic school children aged 6-12 years in Tamale Metropolis, Journal of Medical and Biomedical Sciences, 2013, 2(3):26-34.

[38] Mwaikambo SA, Leyna GH, Killewo J, et al. Why are primary school children overweight and obese? A cross sectional study undertaken in Kinondoni district, Dar-es-salaam, BMC public health, 2015, 15(1):1269.

[39] Roos E, Pajunen T, Ray C, et al., Does eating family meals and having the television on during dinner correlate with overweight? A sub-study of the PRO GREENS project, looking at children from nine European countries, Public Health Nutr., 2014 Nov;17(11):2528-36. doi: 10.1017/s1368980013002954. PubMed PMID: 24642340, eng.

[40] Wilkie HJ, Standage M, Gillison FB, et al, Multiple lifestyle behaviours and overweight and obesity among children aged 9-11 years: results from the UK site of the International Study of Childhood Obesity, Lifestyle and the Environment, BMJ Open, 2016 Feb 24;6(2):e010677, doi: 10.1136/bmjopen-2015-010677, PubMed PMID: 26911589, PubMed Central PMCID: PMCPmc4769406. eng. 